\title{
Plasma Catecholamines and Social Behavior in Male Vervet Monkeys (Cercopithecus aethiops sabaeus)
}

\author{
JAMES E. DILLON, ${ }^{* 1}$ MICHAEL J. RALEIGH, $¥ \S$ MICHAEL T. MCGUIRE, $†$ \\ DEBORAH BERGIN-POLLACK, $\$$ AND ARTHUR YUWILER $\$$
}

*Department of Psychiatry, University of Michigan School of Medicine, Ann Arbor, MI 48109-0390, †Department of Psychiatry and Biobehavioral Sciences, School of Medicine, University of California at Los Angeles, Los Angeles, CA 90024, ¥Nonhuman Primate Laboratory, Veterans Administration Medical Center, Sepulveda, CA 91413, and \$Neurobiochemistry Laboratory, Brentwood Veterans Administration Medical Center, Los Angeles, CA 90073

\author{
Received 28 May 1991
}

\begin{abstract}
DILLON, J. E., M. J. RALEIGH, M. T. MCGUIRE, D. BERGIN-POLLACK AND A. YUWILER. Plasma catecholamines and social behavior in male vervet monkeys (Cercopithecus aethiops sabaeus). PHYSIOL BEHAV 51(5) 973-977, 1992.-Many investigations in humans indicate that epinephrine, norepinephrine and their ratio may correlate with such traits as social competence, academic achievement, and aggression. However, the socioeconomic, dietary, and environmental confounds accompanying most human studies complicate their interpretation. Social status, aggression, and other social behaviors can be reliably assessed in nonhuman primates under conditions controlling for crucial environmental factors. If interpretation of human studies is correct, dominant and subordinate male vervet monkeys should exhibit distinctive patterns of catecholamine secretion. To test this possibility, seventeen adult male monkeys living in six stable social groups were observed for 6 months. Based on their success in agonistic events, subjects were categorized as dominant or subordinate. Alpha scores were calculated from empirically derived factors to provide a noncategorical measure of dominant behavioral style. Plasma epinephrine and norepinephrine samples obtained from anesthetized subjects did not differ between dominant and subordinate males. Alpha scores, however, distinguished high from low norepinephrine/epinephrine ratio groups. These findings are consistent with studies in humans linking high epinephrine, low norepinephrine, and social competence.
\end{abstract}

Catecholamines Social behavior Social status Vervet monkeys

THE relationship of peripheral catecholamines to emotions and behavior has been studied widely since Cannon (5) recognized the importance of adrenomedullary secretions in physiological and psychological responses to stress. Based primarily upon the responses of normal humans, Funkenstein (15) and Elmadjian et al. (12) proposed that aggressive emotional states were associated with high levels of circulating norepinephrine, while anxious states were associated with high levels of circulating epinephrine. In support of the Funkenstein hypothesis, Fine and Sweeney (13) reported increased norepinephrine among men displaying aggressive responses on projective tests, and Ekkers (11) found elevated normetanephrine excretion in aggressive adolescents. Frankenhaueser (14) documented increased levels of epinephrine in association with anticipation, pain, overstimulation, mental work, and cognitive efficiency.

Subsequent research pointed to the possible use of the ratio of norepinephrine to epinephrine $(\mathrm{NE} / \mathrm{E})$, as an indicator of sympathetic balance in psychopathological states. Peripheral epinephrine and norepinephrine levels can change dramatically in response to biological (40) and psychological (14) stresses. Because the two hormones characteristically change in the same direction (7) their ratio may provide a relatively stable measure reflecting the quality or balance rather than the absolute amount of sympathetic discharge. High urinary NE/E has been reported to be a stable trait among violent psychiatric patients (41), while low NE/E has been documented in patients who have made highly lethal suicide attempts (24). Tennes (38) found high urinary $\mathrm{NE} / \mathrm{E}$ in aggressive children and low NE/E in socially competent children.

The study of nonhuman primates allows direct experimental control of some of the social environmental variables that confound human studies such as group composition, group stability, social status, nutritional status, and state of arousal, and permits close observation of behavior over extended periods of time. Though many peripheral biochemical correlates of social behavior have been studied in nonhuman primates, including

\footnotetext{
' Requests for reprints should be addressed to James E. Dillon.
} 
whole blood serotonin $(31)$, testosterone $(9,33)$, cortisol $(8,18,22)$, prolactin (8), glucose (34), and platelet monoamine oxidase (32), norepinephrine and epinephrine have received less attention. Studying rhesus monkeys, Mason et al. (20) reported that plasma norepinephrine rose in response to a variety of emotional stimuli but that epinephrine rose more selectively, usually in response to noxious stimuli prompting subjects to perform a specific task. Chair restraint provoked threefold increases in urinary catecholamines (21). Candland and Leshner (4) found a complex relationship between total urinary catecholamines and social status in small groups of squirrel monkeys (Saimiri squirreus). In a stable social group, rank and urinary catecholamine levels were inversely related: the highest ranking animal among five males exhibited the lowest catecholamine levels. In contrast, in a newly formed group both dominant and subordinate animals tended to exhibit lower catecholamine levels than midranking individuals. These studies suggest that monkeys, like human beings, secrete peripheral catecholamines in response to acute stress, but they do not clarify how social behavior and social status might be related to catecholamine levels.

Vervet monkeys develop relatively stable hierarchical social structures both in free-ranging conditions (6) and in captivity (30). In most vervet colonies, a single, dominant male can be readily distinguished behaviorally (23). Relative to his subordinate counterparts, this male exhibits greater success in agonistic encounters and has preferential access to food and to sexual partners (16). Males appear to achieve dominant social status by establishing affiliative bonds with females rather than through increased aggressivity (29). In this respect they resemble the socially competent children studied by Tennes et al. (38) more than the pathologically aggressive psychiatric patients described by Woodman et al. (42). Correspondingly, if the catecholamine levels observed in the human studies are related to behavioral state rather than to accompanying environmental variables, dominant vervet monkeys should show the low NE/E ratio seen in Tennes competent children rather than the high $\mathrm{NE} / \mathrm{E}$ ratio seen in aggressive children or violent patients. Further, dominant animals should have a lower NE/E ratio than subordinate animals, and males with high scores on separate measures of dominant behavioral style should have similar patterns of catecholamine secretion. In this study we have examined these propositions in monkeys living in stable social groups.

\section{METHODS}

\section{Subjects}

Subjects were seventeen adult male vervet monkeys (Cercopithecus aethiops sabaeus). All were healthy, had fully erupted canines and third premolars, and weighed from $6.4-12.4 \mathrm{~kg}$. Three were ferally raised and fourteen were raised in captivity. Subjects came from six social groups, each consisting of two or three adult males, two to four adult females and their immature offspring. The social composition of the groups had been stable, apart from births, for at least 6 months prior to initiation of the study.

\section{Housing and Care}

As described elsewhere (31), animals were housed in outdoor enclosures at the Nonhuman Primate Laboratory, Sepulveda Veterans Administration Medical Center, Sepulveda, CA.

Animals were fed isoniazid-free commercial monkey chow ad lib, supplemented with fresh fruit once or twice weekly.

\section{Behavioral Observation:}

Behavioral observations were conducted between January and June 1986, when blood specimens for plasma catecholamines were also collected. Sixty focal observations, each lasting $5 \mathrm{~min}$ utes, were conducted for each subject. Behavioral measures were based on Struhsaker's (36) ethogram for this species and are described in Table 1.

Approach, ambivalent approach, groom, sex, aggression, display, submit/avoid, and lipsmack were recorded as initiated when emitted by the target animal and as received when emitted by an interacting subject toward or in response to the target animal. Vigilance was scored only when initiated.

Interrater reliability was calculated for each behavior by dividing the number of times it was scored by both observers by the number of times either or both observers scored it. For all behavioral measures interrater reliability exceeded $85 \%$.

\section{Social Status}

Social status was assessed by observing the outcomes of dyadic intermale agonistic encounters. A subject was regarded as successful in such an encounter if his opponent submitted or avoided in response to a threat, display, or contact aggression initiated by the subject. For each pair of males, the dominant male was the animal with the highest percentage of successes in agonistic encounters. In each group one male was dominant to both of the other two. This animal was defined as the dominant male; other adult males were defined as subordinate.

\section{Blood Samples}

Blood samples were collected between 0730 and 0930 hours. Animals were captured and anesthetized with ketamine hydrochloride (Vetalar), $8-14 \mathrm{mg} / \mathrm{kg}$, approximately 10 minutes (range 5-24 minutes) before femoral venipuncture. Specimens of $3 \mathrm{ml}$ were collected in plastic tubes containing 6 microliters of EGTA and placed on ice. Plasma was frozen within 2 hours of sample collection and stored at $-70^{\circ} \mathrm{C}$.

\section{Catecholamine Assay}

Plasma was assayed for epinephrine and norepinephrine using a commercial modification (Cat-a-Kit, Upjohn) of the technique of Passon and Peuler (25). Interassay variability was approximately $17 \%$ for epinephrine and $14 \%$ for norepinephrine. Assays were rejected when measured concentrations in pooled control specimens supplied by the manufacturer exceeded these limits. Samples from all members of any particular social group collected on a given day were assayed simultaneously. Where multiple specimens were available for a particular subject the mean catecholamine value was used for statistical analysis.

\section{Statistical Analyses}

Statistical procedures were performed with the Statistical Package for the Social Sciences X, version 2.1 (35).

The effect of the blood sampling procedure was assessed by computing correlations (Pearson's $r$ ) between catecholamine levels and time from anesthetization to venipuncture for 19 samples from 13 subjects.

Student's $t$ (one-tailed) compared the mean catecholamine levels and NE/E ratios of dominant and subordinate males.

In subsequent analyses, square root or logarithmic transformations of variables were used where these produced distributions better approximating normality as judged from statistics for skew and kurtosis. 
TABLE 1

BEHAVIORAL REPERTOIRE

\begin{tabular}{|c|c|}
\hline Behavior & Description \\
\hline Approach & $\begin{array}{l}\text { Subject moves within one meter of an } \\
\text { interacting subject and either sits or remains } \\
\text { in proximity for five seconds }\end{array}$ \\
\hline $\begin{array}{r}\text { Ambivalent } \\
\text { approach }\end{array}$ & $\begin{array}{l}\text { Subject moves within a meter of an interacting } \\
\text { subject in a semicrouching posture, typically } \\
\text { with mouth open }\end{array}$ \\
\hline Groom & Animal picks through the fur of another animal \\
\hline Sex & $\begin{array}{l}\text { Any sexual behavior including genital } \\
\text { inspecting, mounting and copulating }\end{array}$ \\
\hline Aggression & All threats and contact aggression \\
\hline Display & $\begin{array}{l}\text { Genital displays, including the red, white, and } \\
\text { blue display and bouncing displays }\end{array}$ \\
\hline Defensive aggress & $\begin{array}{l}\text { A threat in the course of crouching or } \\
\text { retreating }\end{array}$ \\
\hline Submit/avoid & $\begin{array}{l}\text { Crouching, hopping back, screaming, } \\
\text { exaggerated chewing movements, pawing the } \\
\text { ground, or leaving the vicinity in response to } \\
\text { another animal }\end{array}$ \\
\hline Lipsmack & Rapid, repetitive smacking of the lips \\
\hline Vigilance & $\begin{array}{l}\text { Orientation to external stimuli characterized by } \\
\text { a tense, erect posture; all aggression directed } \\
\text { outside an enclosure }\end{array}$ \\
\hline
\end{tabular}

A correlation matrix (Pearson's $r$ ) was generated for all behavioral variables (see Table 1) versus epinephrine, norepinephrine, and $\mathrm{NE} / \mathrm{E}$ ratio.

Factor analysis with varimax rotation based upon seven behavioral variables produced three factors. Of these, two represented behavioral profiles characteristic of dominant and subordinate males, respectively. An alpha score for each subject was computed as the difference between loadings on these two factors.

Correlations (Pearson's $r$ ) were computed between alpha scores and catecholamine variables. In addition, subjects were divided at the median into high $(n=9)$ and low $(n=8) \mathrm{NE} / \mathrm{E}$ groups. Mean alpha scores of these groups were compared using student's $t$.

\section{RESULTS}

\section{Catecholamine Levels in Dominant and Subordinate Males}

Mean levels of catecholamines in dominant and subordinate monkeys are shown in Table 2. No significant differences were found between dominant and subordinate animals with respect to epinephrine, norepinephrine, or NE/E ratio.

\section{Specific Behaviors Versus Catecholamine Levels}

Fifty-one correlations (Pearson's $r$, two-tailed) between seventeen behavioral and three biochemical variables were generated. Seven of these were significant at the 0.05 level: epinephrine with lipsmacks initiated $(r=0.51)$; norepinephrine with lipsmacks received $(r=-0.55)$ and with grooms received $(-0.58)$; and $\mathrm{NE} / \mathrm{E}$ ratio with submits initiated $(r=-0.50)$, with sex initiated ( -0.49$)$, with ambivalent approaches initiated $(r=0.61$, $p<0.01)$, and with defensive aggresses initiated $(r=0.56)$.

\section{Alpha Scores}

Factor analysis produced three factors, two of which appeared to reflect social status. One demonstrated high loadings for ini-
TABLE 2

CATECHOLAMINE LEVELS IN DOMINANT AND SUBORDINATE MONKEYS

\begin{tabular}{|c|c|c|c|c|}
\hline & \multicolumn{2}{|c|}{ Mean \pm SE for Catecholamines* } & \multirow[b]{2}{*}{$t \dagger$} & \multirow[b]{2}{*}{$p$} \\
\hline & $\begin{array}{c}\text { Dominant } \\
(n=6)\end{array}$ & $\begin{array}{l}\text { Subordinate } \\
\qquad(n=11)\end{array}$ & & \\
\hline Epinephrine & $190.67 \pm 20.57$ & $225.88 \pm 33.94$ & -0.72 & 0.76 \\
\hline Norepinephrine & $716.71 \pm 55.94$ & $855.69 \pm 68.05$ & -1.36 & 0.10 \\
\hline $\mathrm{NE} / \mathrm{E}$ & $4.142 \pm 0.498$ & $5.227 \pm 0.838$ & -0.90 & 0.19 \\
\hline
\end{tabular}

* Catecholamines are in $\mathrm{pg} / \mathrm{ml}$

† Student's $t$, one-tailed, $15 d f$.

tiate groom $(0.86)$, initiate sex $(0.76)$, and vigilance $(0.82)$ and negative loading for initiate avoid $(-0.44)$. In five of six social groups the dominant male had a higher loading for this factor than his subordinate cagemates. Another factor was characterized by high loadings for initiate defensive aggress $(0.91)$ and initiate avoid $(0.79)$ and by negative loading for initiate groom $(-0.31)$. In all groups a subordinate male loaded higher than the dominant male on this factor. The difference between these factors (the alpha score) was higher in dominant males than in subordinate males in five of six social groups.

\section{Alpha Scores Versus Catecholamine Levels}

No significant correlations were noted between alpha scores and either epinephrine or norepinephrine. NE/E ratio was significantly correlated with alpha score $(r=-0.49 ; p<0.05$, twotailed). When the subjects were divided into those with high ( $n$ $=9)$ and low $(n=8) \mathrm{NE} / \mathrm{E}$ values, the two groups had mean alpha scores of -0.71 and 0.81 , respectively. These means are significantly different $(t=2.60, p<0.05$, see Fig. 1).

\section{Effects of Time Elapsed Between Anesthetization and Venipuncture}

For 19 samples from 13 subjects the correlations between time elapsed from anesthetization to venipuncture and catecholamine levels were as follows: for epinephrine, $r=-0.45702$,

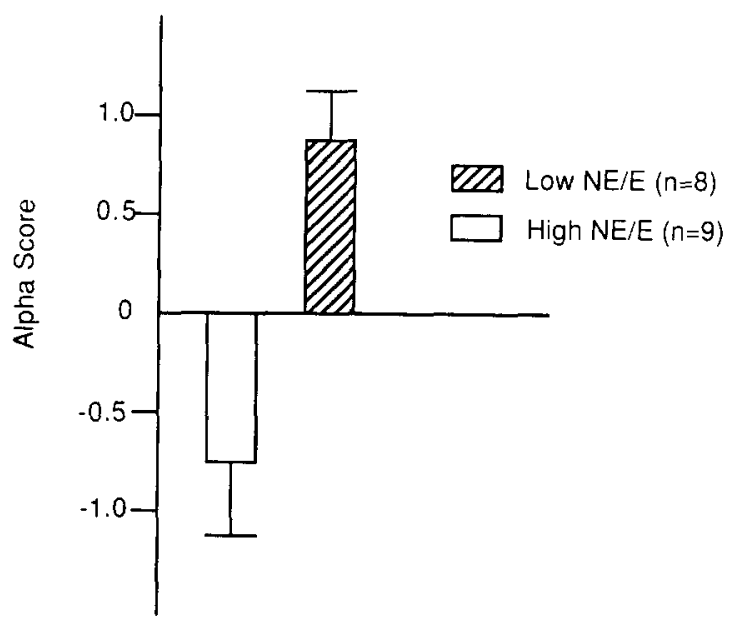

FIG. 1. The mean (and standard error of the mean) alpha scores for the animals with low (cross-hatched) and high (open) NE/E ratios. 
$p<0.05$; for norepinephrine, $r=-0.54734, p<0.01$. These indicate declining catecholamine levels with passage of time after anesthetization. The $\mathrm{NE} / \mathrm{E}$ ratio, however, was not significantly correlated with time elapsed after venipuncture.

\section{DISCUSSION}

These results suggest that, among captive adult male vervet monkeys, social behaviors associated with dominance, such as initiation of sex and receipt of grooming, and lipsmacking, correlate negatively with plasma norepinephrine or $\mathrm{NE} / \mathrm{E}$ ratio; while behaviors associated with submissiveness, such as lipsmacking, submitting, ambivalent approaching, and defensive aggression, correlate positively with NE/E ratio. The number of correlations, seven of 51 yielding significance at the 0.05 level, is well in excess of chance expectation. Furthermore, alpha scores, derived from factor analysis, are significantly negatively related to the NE/E ratio. Contrary to our hypothesis, no straightforward relationships were detected between biochemical measures and social rank as such.

The present findings are compatible with human studies relating social behavior and plasma catecholamine levels. Tennes et al. (38) showed associations in children between social competence and low norepinephrine, between affiliative behavior and high epinephrine, and between socially inappropriate aggression and high NE/E ratio. Bergman and Magnusson (3) described high urinary catecholamine levels, especially epinephrine, in boys characterized as overambitious and overachieving. Our results on vervet monkeys displaying dominant behavioral characteristics supports the association between low NE/E ratio and social competence, ambition, and overachievement. The findings are also consistent with other data from vervets indicating that, in response to stress and competition, the potentially dominant monkeys have higher levels of cortisol (22).

Many factors can influence sympathetic activity. The stress of the anesthetization procedure as well as the anesthesia itself may stimulate catecholamine secretion, though the rapid clearance and metabolism of epinephrine and norepinephrine (17) mitigates this effect in samples obtained several minutes after induction. Differential rates of metabolism of catecholamines, however, may produce differences in circulating levels unrelated to rates of release of these compounds. Ketamine may also influence sympathetic function (39). In human beings catecholamine levels have been reported to rise and peak $3-10$ minutes after ketamine induction $(1,43)$ and after combined ketamine and suxamethonium administration (37), though Takki et al. (37) were unable to demonstrate this phenomenon using ketamine as the sole anesthetic. In the present study, negative correlations between time after anesthetization and catecholamine levels suggest that our samples were collected as catecholamines descended from peak levels, perhaps stimulated by ketamine, capture, and/or injection. NE/E ratio, however, did not change as a function of time after anesthetization. Since norepinephrine and epinephrine are highly intercorrelated (7) and tend to respond to behavioral and biochemical stressors by changes in the same direction (40), the NE/E ratio is probably less vulnerable to such stress effects than the absolute level of either hormone.

This is among the first reports of a relationship between plasma catecholamine levels and social behavior in an anesthetized subject of any species. Anesthetization obviates the need to maintain an indwelling catheter in an animal chronically restrained outside its accustomed social milieu $(19,26)$ and reduces the impact of poorly controlled exogenous factors tending to influence catecholamine levels. In future studies. an anesthetic. and/or a procedure having less effect on sympathetic function (2) might be employed. Study of the sympathomedullary system in animals poses challenging technical difficulties whether the animal studied is awake or unconscious; both approaches may be valuable in further illuminating the relationships between peripheral catecholamines and hehavior.

\section{ACKNOWLEDGEMENTS}

This research was supported in part by the National Institute of Mental Health grants 5-T32-MH16381-05 and 5-T32-MH16381-08 while the first author was a research fellow in child psychiatry at the Neuropsychiatric Institute, University of California. Los Angeles, and in part by the Research Service of the Brentwood and Sepulveda Veterans Administration Hospitals. The guidance of Peter Tanguay, the advice of Gary Brammer, and the technical assistance of Dan Diekman. Nuria Kimble. Glenville Morton, David Torigoe, and Jennifer White were invaluable in the conduct of this research.

\section{REFERENCES}

1. Appel, E. R.; Simrock, R.; Palm, D.; Wnuk, A.; Dudziak, R. Enhancement of sympatho-neuronal and sympathoadrenal activity during ketamine anesthesia. Naunyn Schmiedeberg's Arch. Pharmacol. 297(Suppl):R59; 1977.

2. Baum, D.; Halter, J. B.; Taborsky, G. J.. Jr.; Porte, D., Jr. Pentobarbital effects on plasma catecholamines: Temperature, heart rate and blood pressure. Am. J. Physiol. Endocrinol. Metab. 48(11):E95E100; 1985 .

3. Bergman, L. R.; Magnusson, D. Overachievement and catecholamine excretion in an achievement-demanding situation. Psychosom. Med. 41:181-188; 1979

4. Candland, D. K.; Leshner, A. I. A model of agonistic behavior: Endocrine and autonomic correlates. In: DiCara, L. V., ed. Limbic and autonomic nervous systems research. New York: Plenum Press: 1974

5. Cannon, B. Bodily changes in pain, hunger, fear and rage. New York: Appleton: 1929.

6. Cheney, D. L. Interactions and relations between groups. In: Smuts, B.; Cheney, D. L.; Seyfarth, R. M.; Wrangham, R. W.: Struhsaker, T. T., eds. Primate societies. Chicago: University of Chicago Press; 1987.

7. Curtis, G. C.; Cleghorn, R. A.; Sourkes, T. L. The relationship between affect and the excretion of adrenaline, noradrenaline, and 17 hydroxycorticosteroids. J. Psychosom. Res. 4:176-184; 1960.
8. Eberhart, J. A.; Keverne, E. B,; Meller, R. E. Social influences on circulating levels of cortisol and prolactin in male talapoin monkeys. Physiol. Behav. 30:361-369; 1983.

9. Eberhart, J. A.; Keverne, E. B.; Meller, R. E. Social influences on plasma testosterone levels in male talapoin monkeys. Horm. Behav. $14: 247-266 ; 1980$

10. Eichelman, B. Neurochemical and psychopharmacologic aspects of aggressive behavior. In: Meltzer, H. Y., ed. Psychopharmacology: The third generation of progress. New York: Raven Press; 1987.

11. Ekkers, C. L. Catecholamine excretion, conscience function and aggressive behavior. Biol. Psychol. 3:15-30; 1975

12. Elmadjian, F.; Hope, J. M.; Lamson, E. T. Excretion of epinephrine and norepinephrine in various emotional states. J. Clin. Endocrinol. Metab. 17:608-620; 1957.

13. Fine, B. J.; Sweeney, D. R. Personality traits, situational factors, and catecholamine excretion. J. Exp. Res. Perspect. 3:15-27; 1968.

14. Frankenhaeuser, M. Behavior and circulating catecholamines. Brain Res. 31:241-262; 1971.

15. Funkenstein, D. H. Nor-epinephrine-like and epinephrine-like substances in relation to human behavior. J. Nerv. Ment. Dis. 124:58$68 ; 1956$.

16. Keddy, A. Female mate choice in vervet monkeys. Am. J. Primatol. $10: 125-134 ; 1986$ 
17. Kopin, I. J. Biochemical assessment of peripheral adrenergic activity. In: Usdin, E.; Kopin, I. J.; Barchas, J. Catecholamines: Basic and clinical frontiers, vol. 1. New York: Pergamon; 1978.

18. Manogue, K. R.; Leshner, A. I.; Candland, D. K. Dominance status and adrenocortical reactivity to stress in squirrel monkeys (Saimiri sciureus). Primates 16:457-463; 1975.

19. Mason, J. W. Restraining chair for the experimental study of primates. J. Appl. Physiol. 12:130-133; 1958.

20. Mason, J. W.; Manajan, G., Jr.; Brady, J. V.; Conrad, D.; Rioch, D. Concurrent plasma epinephrine, norepinephrine and 17-hydroxycorticosteroid levels during conditioned emotional disturbances in monkeys. Psychosom. Med. 23:344-353; 1961.

21. Mason, J. W.; Mougey, E. H.; Kenion, C. C. Urinary epinephrine and noradrenaline responses to chair restraint in the monkey. Physiol. Behav. 10P:801-804; 1973.

22. McGuire, M. T.; Brammer, G. L.; Raleigh, M. J. Resting cortisol levels and the emergence of dominant status among male vervet monkeys. Horm. Behav. 20:106-117; 1986.

23. McGuire, M. T.; Raleigh, M. J.; Johnson, C. Social dominance in adult male vervet monkeys. I: General considerations. Soc. Sci. Info. $22: 89-124 ; 1983$

24. Ostroff, R. B.; Giller, E.; Harkness, L.; Mason, J. The norepinephrineto-epinephrine ratio in patients with a history of suicide attempts. Am. J. Psychiatry 142:224-227; 1985.

25. Passon, P. G.; Peuler, J. D. A simplified radiometric assay for plasma norepinephrine and epinephrine. Anal. Biochem. 51:618-631; 1973.

26. Perlow, M. J; Karoum, F.; Braun, D.; Wyatt, R. J. Adrenergic and dopaminergic responses to chronic chair restraint in the rhesus monkey. Psychosom. Med. 41:139-145; 1979.

27. Raleigh, M. J.; Brammer, G. L.; McGuire, M. T.; Yuwiler, A. Dominant social status facilitates the behavioral effects of serotonergic agonists. Brain Res. 348:274-282; 1985.

28. Raleigh, M. J.; Brammer, G. L.; Yuwiler, A.; Flannery, J. W.; McGuire, M. T.; Geller, E. Serotonergic influences on the social behavior of vervet monkeys (Cercopithecus aethiops sabaeus). Exp. Neurol. 68:322-334; 1980.

29. Raleigh, M. J.; McGuire, M. T. Female influences on male dominance acquisition in captive vervet monkeys, Cercopithecus aethiops sabaeus. Anim. Behav. 38:59-67; 1989.
30. Raleigh, M. J.; McGuire, M. T. Social influences on endocrine function in male vervet monkeys. In: Ziegler, T. E.; Bercovitch, F. B. eds. Socioendocrinology of primate reproduction. New York: WileyLiss; 1990.

31. Raleigh, M. J.; Mcguire, M. T.; Brammer, G. L.; Yuwiler, A. Social and environmental influences on blood serotonin concentrations in monkeys. Arch. Gen. Psychiatry 41:405-410; 1984.

32. Redmond, D. E.; Murphy, D. L.; Baulu, J. Platelet monoamine oxidase activity correlates with social affiliative and agonistic behaviors in normal rhesus monkeys. Psychosom. Med. 41:87-100; 1979.

33. Rose, R. M.; Gordon, T. P.; Bernstein, I. S. Plasma testosterone levels in the male rhesus: Influences of sexual and social stimuli. Science 178:643-645; 1972 .

34. Shively, C.; Kaplan, J. Effects of social factors on adrenal weight and related physiology of Macaca fascicularis. Physiol. Behav. 33: $777-782 ; 1984$

35. SPSS, Incorporated. SPXX-X user's guide, edition 2. Chicago: SPSS, Inc.; 1986.

36. Struhsaker, T. T. Behavior of vervet monkeys (Cercopithecus aethiops sabaeus). Univ. Calif. Publs. Zool. 82:1-64; 1967.

37. Takki, S.; Nikki, P.; Jaattela, A.; Tammisto, T. Ketamine and plasma catecholamines. Br. J. Anaesth. 44:1318-1322; 1972.

38. Tennes, K.; Kreye, M.; Avitable, N.; Wells, R. Behavioral correlates of excreted catecholamines and cortisol in second-grade children. J. Am. Acad. Child Psychiatry 25:764-770; 1986.

39. Traber, D. L.; Wilson, R. D. Involvement of the sympathetic nervous system in the pressor response to ketamine. Anesth. Analg. 48:248$252 ; 1969$.

40. Vigas, M.; Kvetnansky, R.; Jurcovicova, J.; Jezova, D.; Tatar, P. Comparison of catecholamine and adrenopituitary hormone responses to various stress stimuli in man. In: Usdin, E.; Kvetnansky, R.; Axelrod, J., eds. Stress: The role of catecholamines and other neurotransmitters, vol. 2. New York: Gordon and Breach; 1983.

41. Woodman, D. D. Evidence of a permanent imbalance in catecholaminine secretions in violent social deviants. J. Psychosom. Res. 23:155-157: 1979 .

42. Woodman, D. D.; Hinton, J. W.; O'Neill, M. T. Plasma catecholamines, stress and aggression in maximum security patients. Biol. Psychiatry 6:147-154; 1978 .

43. Zsigmond, E. K. Comment. Anesthesia and analgesia 51:595-596; 1972. 